\title{
A essência platônica da tradução ${ }^{1}$
}

\author{
Antoine Berman
}

Tradução de Gilles Jean Abes* e revisão de Simone Petry**

Questionar-se a respeito do "platonismo" da tradução significa, em primeiro lugar, questionar-se sobre o elo profundo que une o traduzir e o filosofar como tal. Este elo é mais decisivo que aquele que une, por exemplo, a tradução à literatura ou à religião, pois consiste no seguinte: para cada figura (histórica) da verdade filosófica corresponde (sem nenhuma relação de "causalidade") certa figura histórica da verdade do traduzir que o determina tanto em sua "prática" quanto em sua "teoria". Assim, como veremos, corresponde ao platonismo certa "definição" da tradução (a restituição do "sentido" como idealidade do texto), corresponde ao cartesianismo e à sua metafísica da clareza a tradução como produtora de "luzes", corresponde ao idealismo alemão a tradução como "elevação à potência" dos originais etc. E isso é possível, postularemos, somente porque existe um tipo de "afinidade secreta" entre o filosofar e o traduzir através da diversidade histórica de suas figuras. A filosofia está ligada à tradução, e vice-versa.

\footnotetext{
1 "L'essence platonicienne de la traduction". Esse texto é uma versão adaptada de um seminário sobre a tradução e a filosofia que ocorreu no Collège International de Philosophie em janeiro de 1985. Publicado na Revue d'Esthétique (Nouvelle série), Nº 12 (1986). Toulouse, éditions Privat, 1987. [N. do autor] As notas sem indicação de minha autoria são de Antoine Berman.

* Universidade Federal de Santa Catarina (UFSC)

** Pós-doutoranda do Programa de pós-graduação em Estudos da Tradução-PGET, da Universidade Federal de Santa Catarina-UFSC
} 


\section{Platonismo e língua}

Coloquemos, de forma bem tradicional, que o platonismo é aquela figura do pensamento ocidental que instaurou um corte decisivo entre o "sensível" e o "não sensível", corte no qual o sensível é ontologicamente desvalorizado em relação ao não sensível, que, doravante, torna-se o "suprassensível". A alma, Sócrates não cessa de afirmá-lo, deve abandonar a prisão da corporeidade para ganhar a planície das "ideias", ou seja, do "aspecto" imutável das coisas. A partir daí, uma série de oposições bastante conhecidas: transitório e eterno, corruptível e incorruptível, tangível e intangível, obscuro e luminoso, múltiplo e uno, verdadeiro e falso etc.

Filosofar significa passar da primeira região à segunda, ou realizar o vaivém "dialético" entre as duas.

Podemos perceber a que ponto esse corte perturba a experiência grega anterior ao comparar o eros que atravessa a poesia de Safo e aquele do Banquete ou do Fedro de Platão. O movimento "erótico" dos poemas sáficos jamais separa o desejo do singular sensível disso que, nesse singular, é da ordem do imperecível e do "glorioso": no caso da poeta, esta mulher, e $A$ Mulher, a Ideia de Mulher. Safo mantém os dois juntos. O platonismo começa ali onde o singular e o universal são separados; ali onde esta mulher não é senão a sombra, o reflexo, a cópia da Ideia de Mulher. Nesta cisão surge certa figura do pensamento, do saber e da "experiência" em geral, e isso é bastante visível na história da poesia ocidental, de Petrarca a du Bellay, de Racine a Mallarmé, até Valéry e, ainda mais recente, até Bonnefoy. No horizonte platônico, a poesia é dilacerada entre a "linguagem das coisas" e a "linguagem dos Deuses" (Valéry).

Ora, essa cisão atinge necessariamente a tradução porque atravessa, talvez acima de tudo, a própria linguagem, na medida em que seus elementos, o som e a letra de um lado, a significação e o sentido de outro, suportam a estrutura de qualquer língua. A linguagem é sensível e não sensível. De maneira mais precisa: é a partir do platonismo que pensamos a linguagem sob este duplo aspecto. Na medida em que a tradução se move na linguagem, não pode não ser afetada por essa experiência. Mais ainda: é no horizonte da percepção platonicizante da linguagem, do logos, que, em Alexandria e depois em Roma, foram definidas a teoria e a prática da tradução. Quando São Jerônimo, após Cícero, enuncia o que é, para ele, o princípio de base do traduzir, "non verbum e verbo sed sensum exprimere de 
sensu"2, ele o faz a partir da experiência da língua instaurada pelo platonismo, como se o "sentido" e a "letra" pudessem ser dissociados, e, sobretudo, como se o "sentido" tivesse mais ser do que a "letra", constituindo o que, de uma língua para outra, não "varia".

No entanto, o simples fato de que, historicamente, tradução e linguagem tenham sido definidas no horizonte categorial do platonismo não basta para falar em uma essência platônica da tradução. É preciso que, ao escrutinar o próprio ato de traduzir e o trabalho sobre a língua que lhe é próprio, reencontremos algo que o aparente, estruturalmente, ao filosofar do platonismo. Não são estas ou aquelas práticas ou teorias do traduzir que são "platônicas", mas sim a tradução em si em certa dimensão de seu ser. Isso não significa (ao contrário) que ela seja reduzível a essa dimensão. Mas para perceber o que a tradução tem também de "não platônico", é necessário ter mensurado o que, nela, sempre e em toda parte, a associa irremediavelmente ao platonismo.

\section{Deixar cair o corpo para fazer irromper o sentido}

Nada parece melhor definir o platonismo fundamental da tradução do que essas linhas de Jacques Derrida: “Um corpo verbal não se deixa traduzir ou transportar em outra língua. Ele é aquilo mesmo que a tradução deixa cair. Deixar cair o corpo, eis em si a energia essencial da tradução". ${ }^{3}$

Aqui, cada palavra repercute: "deixar cair", "corpo", "energia". A tradução encontra sua força própria ao afastar o "significante" para captar o "significado", pois não se traduz "palavras", mas "sentidos". Proposição muita repetida que ainda é ensinada em todas as escolas de tradução, mas que Derrida nos convida a meditar sobre seu horizonte metafísico, afinal "deixar cair o corpo" é exatamente o que não cessa de dizer Sócrates, em outro contexto. Podemos dizer que ao traduzir realizamos, no domínio da

\footnotetext{
2 “[...] na tradução dos gregos não busco expressar uma palavra a partir de outra palavra, mas o sentido a partir do sentido." Tradução de Mauri Furlan. "Brevíssima história da teoria da tradução no ocidente: Idade Média." Cadernos de tradução. n. 12. Florianópolis: PGET, 2005. [N. do tradutor]

3 "Un corps verbal ne se laisse pas traduire ou transporter dans une autre langue. Il est cela même que la traduction laisse tomber. Laisser tomber le corps, telle est même l'énergie essentielle de la traduction." Derrida, Jacques. L'écriture et la différence. Paris : Seuil, coll. «Points», p. 312. [Trad. Minha] Optei por manter os exemplos em francês (e em outros idiomas) com a tradução em português (quando necessária) para melhor apreender a argumentação de Berman. Todas as traduções das citações e exemplos são de minha autoria (corpo do texto, entre colchetes ou em nota de rodapé), salvo menção contrária. [Nota do tradutor]
} 
linguagem e das obras, a própria essência do filosofar; e que podemos averiguá-lo. Graças à tradução, o sentido de fato aparece como que apartável da letra. Se manifesta como diferente e apartável da letra. Traduzir separa o "significante" do "significado", o sensível do não sensível. Mais: essa separação, em sua própria violência, indica que, na linguagem, o único elemento verdadeiro, ou seja, autônomo, imutável e invariável, é o sentido. Ao liberá-lo de sua canga linguajar, a tradução mostra e realiza a separação platônica. O sentido não está mais em uma língua, tornou-se aquele invariante passando (se "transladando") de uma língua a outra, e, portanto, distanciando-se de todas.

Mais ainda: a tradução, ao revelar o que passa de uma língua para outra, dá a ver sua base comum. A totalidade do que é "traduzível" desenha um negativo do que é a linguagem em sua idealidade, desvela o que, em cada língua, é da ordem da particularidade ou, ao contrário, ao encontrar-se nas outras línguas, é "universal". Ou ainda: a tradução, ao revelar fotograficamente o traduzível e o intraduzível, revela também a língua que está em toda língua e que faz com que toda língua seja uma língua. A pedra de toque da "verdadeira" linguagem é a traduzibilidade. E o que, numa língua, não se deixa traduzir, é o que não diz respeito à sua verdade de linguagem.

Resumindo: que se trate das palavras ou da língua em sua totalidade, a tradução é o que dá a ver pela primeira vez o sentido como idealidade invariante.

\section{Tradução e reformulação}

Poderíamos objetar aqui, com Valéry, Jakobson, Benveniste e, além deles, Derrida, as duas seguintes questões. Primeiro, que a tradução em si é tornada possível pelo corte entre significante e significado, e, portanto, não funda essa cisão. Em seguida, que existem outras operações no seio da língua que manifestam a idealidade do sentido. Por fim, que é bastante arriscado escrever como o faz Lacan (num contexto que lhe é próprio, é verdade) que “o sentido jamais é produzido ao não ser da tradução de um discurso num 
outro" ${ }^{4}$, sobretudo se entendermos como tradução somente o translado interlíngua, como é o caso.

Mas escutemos o que diz Derrida (aqui, em pleno acordo com a linguística moderna) a propósito da condição de possibilidade da tradução:

Há tradução, sistema de tradução, somente se um código permanente permite substituir ou transformar os significantes preservando o mesmo significado, ainda presente apesar da ausência desse ou daquele significante determinado. A possibilidade radical da substituição estaria assim implicada pelo par de conceitos significado/significante, portanto, pelo próprio conceito de signo. ${ }^{5}$

Parece incontestável, e no nosso contexto, é preciso dizer que é a estrutura "platônica" da linguagem que permite o traduzir.

Não obstante, vou tentar demonstrar (sem nenhuma pretensão à cientificidade) que, longe de fundar-se sobre essa estrutura, a tradução é o único ato que efetua e concretiza essa cisão. E neste ponto, é preciso retornar à segunda objeção: trata-se de um poder unicamente reservado à tradução interlíngua? Sabemos que Jakobson distinguiu três tipos de tradução: a interlinguística, a intralinguística (o rewording) e a intersemiótica.

Não poderíamos afirmar que o rewording manifesta o mesmo poder "metalinguístico" que a tradução? Que a possibilidade de formar várias cadeias significantes para uma mesma série de significados equivale igualmente a uma produção e manifestação do "sentido"? Que a reformulação, tal qual a tradução, também faz irromper sentido puro? Em síntese, que a pesquisa por um sentido "equivalente" no seio de uma língua é idêntica àquela por um sentido "equivalente" em outra língua?

Não creio que, numa mesma língua, na medida em que forma um sistema homogêneo (ainda que diferenciado internamente), seja possível enunciar a mesma coisa com outras palavras. "Gosse" [guri] e "moutard" [moleque] têm o mesmo referente, mas a significação dessas palavras é a "mesma"? Seriam intercambiáveis? "Je me suis levé tôt" [acordei cedo] diz a mesma coisa que "je me suis levé de bonne heure" [acordei em boa

\footnotetext{
4 "le sens ne se produit jamais que de la traduction d'un discours dans un autre". Lacan, Jacques. "L'Etourdit", Scilicet, n. 4, 1973, p. 36.

5 “il n'y a de traduction, de système de traduction, que si un code permanent permet de substituer ou de transformer les signifiants en gardant le même signifié, toujours présent malgré l'absence de tel ou tel signifiant déterminé. La possibilité radicale de la substitution serait donc impliquée par le couple de concepts signifié/signifiant, donc par le concept de signe lui-même". Derrida, Jacques. Op. cit. , p. 311.
} 
hora/cedo]? A certo nível de banalização das formulações, certamente. Mas esse nível (o do laboratório de línguas ou do cotidiano mais banal), é o nível no qual a língua não fala. Ainda que se deva levar em conta a existência desse nível, é impossível fazer dele a essência da linguagem. A palavra oca não é senão a decadência da palavra plena; e é porque a linguagem é originariamente plena que pode ser igualmente, e mais frequentemente, vazia. A palavra oca é um possível do falar em geral, a possibilidade que tem de cair no que Heidegger, em O Ser e o Tempo, chama de Gerede, falação. Mas assim que se abandona essa região do falar (e da escrita), assim que se aborda os domínios nos quais oral e escrita são plenas (que se trate de um diálogo amoroso ou de um poema), é evidente que não se pode dizer "a mesma coisa de outra maneira"; que "je me suis levé tôt" e "je me suis levé de bonne heure" não são exatamente equivalentes. Não se pode dizer "de outra maneira" em uma mesma língua, porque em todos os domínios essenciais da palavra e da escrita, como diz a língua comum, cada palavra "conta" ou "repercute". A ideia segundo a qual eu posso dizer a mesma coisa de outra maneira pressupõe, na verdade, que a língua é tão somente um imenso estoque de termos e formas dos quais posso fazer uso à minha maneira para enunciar meu "querer-dizer". Mas ainda que eu tivesse tal visada, e considerasse que posso dizer o que digo de várias maneiras, o fato é que, na língua, o sentido está tão ligado à letra que se houver uma mínima mudança do meu enunciado, é a totalidade do que eu "quis dizer" que corre o risco de pender para outro registro do sentido e me fazer dizer algo totalmente diferente do que eu quis dizer. Em outras palavras: por não ser o mestre da linguagem, e esta não sendo um instrumento, não posso dizer realmente a mesma coisa de outra maneira, pelo menos sem correr o risco de ser tomado pela deriva de sentido produzido.

Lacan caracterizou muito bem esse estado das coisas:

[...] o sistema simbólico é formidavelmente intricado. [...] Todo símbolo linguístico facilmente isolado é não somente solidário ao conjunto, mas é recortado e constituído por toda uma série de afluências, de sobredeterminações oposicionais que o constituem simultaneamente em vários registros. Esse sistema da linguagem, no qual se desloca nosso discurso, não é algo que ultrapassa infinitamente toda intenção que possamos ter e que permanece apenas momentânea? ${ }^{6}$

\footnotetext{
${ }_{6}$ “Tout symbole linguistique aisément isole est non seulement solidaire de l'ensemble, mais se recoupe et se constitue par toute une série d'affluences, de surdéterminations oppositionnelles qui le constituent à
} 
A reformulação não pode fazer irromper sentido porque ela é um mito, ou antes um eterno engodo do sujeito falante, que, além disso, frequentemente paga caro pela pretensão de dizer a mesma coisa de outra maneira. Para que apareça sentido, deve haver heterogeneidade de dois sistemas significantes, e esta se encontra tão somente na diferença interlinguística. Digamos então: não podemos definir a tradução em termos de reformulação, mas podemos (afinal é o que faz Jakobson, e isso mantém um valor ao menos metafórico) definir a reformulação em termos de tradução. É por essa razão que o conceito de tradução é bem mais central para a teoria da linguagem do que o de reformulação.

\section{Língua traduzida e língua traduzinte}

Mas a questão da reformulação não está esgotada. Pois o próprio da tradução é não somente mirar o que a reformulação não pode realizar, re-enunciar o mesmo de outro modo, mas também colocar o traduzido no espaço da reformulação, tornar tal espaço não somente possível, mas vertiginosamente real.

O espaço da reformulação é o da liberdade do sentido, na medida em que este não está mais ligado, não está mais fixado a uma letra.

Sem dúvida a tradução não destaca um significado senão para acoplá-lo (se pudermos dizer dessa forma) ao significante de outra língua. Com o que mais poderíamos acoplá-lo? Mas a relação global do significado e do significante na língua traduzida não é a mesma do que na língua traduzinte. Ela é fundamentalmente "flutuante". Na língua traduzida, o sentido está ligado à letra, já que não há reformulação possível. Isso significa que nesta língua, nós nos encontramos sob a lei da letra. Na língua traduzinte, ao contrário, nos encontramos sob a lei do sentido ${ }^{7}$. O que é dito em língua de origem não é re-enuciável, o que é dito ou escrito na língua de chegada é.

\footnotetext{
la fois dans plusieurs registres. Ce système du langage, dans lequel se déplace notre discours, n'est-il pas quelque chose qui dépasse infiniment toute intention que nous pouvons y mettre et qui est seulement momentanée?". Lacan, Jacques. Le Séminaire, Paris, Le Seuil, Tome I, p. 65.

${ }^{7}$ É a o que parece aludir Benjamin quando escreve em A tarefa do tradutor: "Le rapport de la teneur au langage est tout à fait différent dans l'original et dans la traduction. Dans l'original, teneur et langage forment une unité déterminée, comme celle du fruit et de l'enveloppe; le langage de la traduction enveloppe sa teneur comme un manteau royal aux larges plis. " "[...] a relação que o teor interno [Gehalt] estabelece com a língua é completamente diversa no original e na tradução. Pois, se no original eles formam certa unidade, como casca e fruto, na tradução, a língua recobre seu teor em amplas pregas, como um manto real." Tradução de Susana Kampff Lages. Nota da tradutora: Benjamin estabelece, em seu
} 


\section{Alguns "exemplos"}

Essas afirmações ficarão mais claras com uma série de exemplos. Eis, para começar, a primeira frase de O Processo de Kafka:

Jemand musste Josef K. verleumdet haben, denn ohne dass er etwas Böses getan hätte, wurde er eines Morgens verhaftet.

[Alguém certamente havia caluniado Josef K. pois uma manhã ele foi detido sem ter feito mal algum. ${ }^{8}$ ]

Tomo emprestado esse exemplo de Christine Toutin', que fornece as três traduções existentes dessa frase, além de outras viáveis.

\section{Vialatte:}

On avait sûrement calomnié Joseph $K$. , car, sans avoir rien fait de mal, il fut arrêté un matin.

[Tinham certamente caluniado Joseph K., pois, sem ter feito mal algum, ele foi detido uma manhã.]

\section{Goldschmidt:}

Quelqu'un avait dû calomnier Joseph $K$, car, sans avoir rien fait de mal, il fut arrêté un matin.

[Alguém devia ter caluniado Joseph K., pois, sem ter feito mal algum, ele foi detido uma manhã.]

\section{Lortholary:}

Il fallait qu'on ait calomnié Joseph K. : un matin, sans avoir rien fait de mal, il fut arrêté.

ensaio, sobre o romance As afinidades eletivas, de Goethe, uma distinção entre Gehalt e Inhalt, palavras sinônimas que indicam conteúdo, teor. Para preservar a distinção, optamos sempre que possível pela palavra teor.

${ }^{8}$ Tradução de Modesto Carone. O Processo. - São Paulo: Companhia das Letras, 1997. [N. do Tradutor]

9 Toutin, Christine. “A travers les langues.” Littoral, Paris, n. 13, 1984, p. 48. 
[Houve certamente quem caluniasse Joseph K.: uma manhã, sem ter feito mal algum, ele foi detido.]

Toutin propõe:

Il fallait que quelqu'un ait calomnié Joseph $K$. car, sans qu'il ait fait quelque chose de mal, il fut arrêté un matin.

[Houve certamente alguém para caluniar Joseph K. pois, sem que tivesse feito algo de mal, ele foi detido uma manhã.]

Quelqu'un devait avoir calomnier Joseph $K$, car, sans qu'il ait fait quelque chose de méchant, il fut arrêté un matin.

[Alguém devia ter caluniado Joseph K., pois, sem que tivesse feito alguma coisa má, ele foi detido uma manhã.]

E, claro, outras traduções seriam possíveis. Ainda que seu número não seja linguisticamente ilimitado, situamo-nos, aqui, na infinidade do reformulável. Enquanto lá no original a frase é única, intangível e imutável como ato de escritura. O tradutor pode certamente tentar "colar ao estilo" de Kafka e reduzir a margem de transformabilidade, mas esta permanece, com a lei seguinte: pode-se (deve-se) re-traduzir Kafka, não se pode (não se deve) re-escrevê-lo. E daquela série de versões possíveis da frase original se destaca um único elemento invariante, seu "conteúdo". O "sentido" da frase, que aparece sobre as ruinas de sua letra. Sobre as ruinas, pois todas as reformulações das traduções se relativizam entre si e, portanto, se destroem mutuamente. Toutin observa que esse fenômeno de tradução "em cascata" produz um efeito cômico; em todo caso, um efeito irônico, caso a ironia irrompa da relativização dos enunciados. Mas se a letra é aniquilada na tradução, o sentido, ele, está salvo e triunfante. A invariância do sentido substituiu a invariância da letra. No que diz respeito à obra. Mas a tradução também modificou a relação do significado e do significante na língua traduzinte, que se tornou veículo de um sentido, e não mais letra na qual o sentido está detido. $O$ francês de uma tradução, portanto, não é o de um texto escrito originalmente nessa língua. Ou ainda: a linguagem da tradução (qualquer seja a língua) é sui generis. 
Comparemos agora um original de Beckett (L'innomable [O inominável]) em francês com sua autotradução em inglês. Isso porque a autotradução manifesta mais abertamente que a heterotradução a ligação ao sentido.

Beckett escreve:

Mais non, ici, tout changemet serait funeste, me ramènerait rue de la Gaîté séance tenante.

[Não, aqui, qualquer mudança seria funesta, me levaria imediatamente de volta à rua de la Gaîté.]

Em inglês:

No, here all change would be fatal and land me back, there and then, in all the fun of the fair.

[Não, aqui toda mudança seria fatal e me levaria de volta, ali mesmo, em toda a diversão da feira.]

$\mathrm{Na}$ versão inglesa, a ideia associada no original ao nome da rua (portanto, alusivamente) é colocada em primeiro plano, explicitada: é a da diversão, da distração. Como veremos, qualquer ênfase de sentido é explicitante e aclaradora.

Em outro lugar, Beckett traduz "tout plutôt que ces propos de khâgneux" por "anything rather than these college quips".

A especificidade de "khâgneux", em francês, desaparece aqui em prol de um sentido mais geral. Com efeito, "quips" significa simplesmente: "sarcasmos, zombarias, palavras picantes".

Quando Beckett traduz "Prix Goncourt" por "Prix Pulitzer", parece que o que contava para ele não era esse prêmio, mas a ideia de um prêmio literário em geral. ${ }^{10}$

Em toda parte, a autotradução de Beckett revela que o essencial para ele, não é a letra do original, mas seu sentido. Certamente, o heterotradutor

10 Ver Lectures (Bari, Dedalo), n. 4-5, "Traduzione tradizione", p. 55; p. 153. Paul Saint-Pierre, "L'innombrable de Samuel Beckett: texte(s) et symbolique." 
dificilmente se permite tais liberdades (ainda que com frequência não se prive delas), mas essas liberdades manifestam um movimento inerente a qualquer tradução: a liberação da significação. E essa liberação equivale a uma universalização, a uma explicitação, a um aclaramento. A uma passagem do "concreto" ao "abstrato".

\section{A desistoricização da língua original}

Ainda podemos chamar essa passagem do concreto ao abstrato de desistoricização da língua da obra. Esta, evidentemente, é de um lado a outro histórica e inserida numa temporalidade. A tradução tende a destruir essa temporalidade em prol de um sentido e uma forma intemporais.

Divertimo-nos um instante comparando uma frase de Proust com uma frase do escritor Hermann Broch traduzida em francês.

Proust:

Et la vue d'un seul coquelicot, hissant au bout de son cordage et faisant cingler au vent sa flamme rouge, au-dessus de sa bouée graisseuse et noire, me faisait battre le coeur comme au voyageur qui aperçoit sur une terre basse une première barque échouée que répare un calfat, et s'écrie, avant de l'avoir vue: "La Mer!".11

[E a visão de uma única papoula, alçando na ponta de seu cordame e fazendo açoitar ao vento sua chama vermelha, acima de sua boia engordurada e preta, fazia bater meu coração como ao viajante que avista sobre uma terra baixa uma primeira barca encalhada que conserta um calafate, e que grita, antes de tê-lo visto: “O Mar!”]

Broch:

Vague de désir déferlant contre vague, entraîné par le courant, un baiser trouva l'autre et, les saules du fleuve croissant et se tendant de rive à rive, les cernant comme un antre de félicité dont la paix enclose abrite le silence du lac éternel, ce fut, tant sa voix s'éteignit, sans plus de souffle, ne cherchant que son haleine à elle, ce fut comme un cri qu'elle entendit: "je t'aime", qui l'ouvrit, l'ouvrit comme le coquillage d'un lac et il sombra en elle sans retour. ${ }^{12}$

${ }^{11}$ Citado por Spitzer, Études de Style, Paris, Gallimard, p. 408.

12 H. Broch. Les Somnanbules, Paris, Gallimard, p. 43. 
[Onda de desejo rebentando contra onda, levado pela correnteza, um beijo encontrou outro e, os salgueiros do rio cruzando e estendendo-se de margem em margem, cercando-os como a um antro de felicidade cuja paz cativa abriga o silêncio do lago eterno, foi, de tanto que sua voz desfaleceu, sem sopro algum, nada procurando senão o hálito dela, foi como um grito que ela ouviu: "Eu te amo", que a abriu, abriu como a concha de um lago e nela naufragou sem volta.]

Linguisticamente, nossa comparação é absurda: temos aí dois textos em francês, e ponto. A frase de Broch, nessa tradução, não deixa sombra de um germanismo. E, no entanto, a diferença entre os textos é abissal. Por quê?

Tomemos Proust. Cada palavra, aqui, "coquelicot" [papoula], "flamme" [chama], "voyageur" [viajante], "barque" [barca], está presa a espaços de ressonância que atribuem a ela seu verdadeiro "valor". Há, primeiro, a inflexão pessoal que o escritor dá, em sua obra, a essas palavras. Mas para além disso, verticalmente, existem todas as inflexões que elas receberam na história da língua e da literatura francesas: os sentidos presentes também em Proust - que puderam ter em Baudelaire, Flaubert, Nerval, Chateaubriand etc. É toda a espessura histórica das palavras, toda sua ancoragem no ser temporal e diacrônico da língua. A frase de Proust está assentada em sua língua como um pássaro em seu ninho, de onde ele pode alçar voo, ou nela enraizada como uma planta. Ler Proust significa entrar no domínio da espessura, da sedimentação significante da letra. Mal poderíamos falar aqui de "sentido", pois toda esta significância acumulada nas palavras não se deixa reduzir ao sentido geral que podem ter.

Diríamos o mesmo da frase de Broch em alemão na qual, por exemplo, as palavras "saule" [salgueiro] e "fleuve" [rio] ressoam por tudo o que puderam significar na história da língua literária alemã, remetem à presença que tiveram nas obras de Hofmannstahl, Stifter, Hölderlin, para citar uma genealogia à qual Broch se identificava.

Mas na tradução? Seguramente, esse enraizamento temporal desapareceu, pois o texto traduzido não tem nenhuma relação com o passado da língua alemã, evidentemente, mas tampouco com o de nossa língua. Isso significa que as palavras "saule" [salgueiro] e "fleuve" [rio] perderam aquela espessura significante e ressoante que possuem no original. 
No entanto, a frase que lemos é bela. Certamente, mas em virtude de outra aura que ela adquiriu, em virtude do que poderíamos chamar sua beleza formal, que substituiu a beleza material do original. Poderíamos até afirmar que a versão francesa de Broch é necessariamente mais transparente, mais cristalina, mais incorporal do que o original. Ela é pura imagem ali onde a frase alemã está presa nessa intricação simbólica, nesse emaranhado de sobredeterminações das quais fala Lacan. E ali onde o alemão ressoa infinitamente como uma cascata de ecos e de retornos, poderíamos afirmar que o francês brilha em absoluta imobilidade.

O mesmo fenômeno de significação transparente pode ser observado a respeito deste verso de Antígona de Sófocles que já analisei várias vezes ${ }^{13}$ :

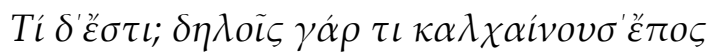

Mazon e Grosjean o traduzem respectivamente por: "De quoi s'agit-il donc? Quelque propos te tourmente, c'est clair" [De que se trata? Alguma questão te atormenta, está claro] e por: “Qu'y a-t-il? Quelque histoire t'assombrit, je le vois." [O que há? Alguma história te assombra, estou vendo].

Ora, o verbo kalkaina [ $\kappa \alpha \lambda \chi \alpha i v \omega]$, nos informa o dicionário, significa na origem "ter a cor da púrpura", "ter um tom escuro". Daí um desvio semântico para "estar sombrio, atormentado".

Hölderlin, sabe-se, traduziu o verso mais literalmente: "Was ist's, $d u$ scheinst ein rottes Wort zu färben?" ("Qu'y a-t-il? Tu sembles teindre une rouge parole"14), privilegiando assim o sentido primeiro do verbo, ali onde Mazon e Grosjean mais classicamente dão o sentido derivado, ou seja, mais abstrato, mais geral. Ora, privilegiar (para bem destacar o sentido da frase) a significação abstrata de kalkaina [ $\kappa \alpha \lambda \chi \alpha i v \omega]$ ], é evidentemente "deixar cair" a significância etimológica e corporal deste verbo. Portanto, desistorializá-lo ali onde, no original, "ter a cor da púrpura" continua ressoando como "ser atormentado".

Hölderlin, retornando ao sentido primeiro do verbo, anuncia outra essência da tradução. O que pretendíamos mostrar com esse exemplo, é como traduções fiéis, de resto, desparticularizam as significâncias do

\footnotetext{
${ }^{13}$ Ver A prova do estrangeiro e $A$ tradução e a letra, ou do albergue do longínquo.

${ }^{14} \mathrm{O}$ que há? Parece tingir uma vermelha palavra.
} 
original para produzir sentido puro e unívoco. E para assim produzir outro tipo de texto, outro tipo de língua, sem espessura e sem temporalidade.

\section{Bonnefoy e Shakespeare}

Yves Bonnefoy percebeu perfeitamente, à sua maneira - e em relação à questão do platonismo, que atravessa toda sua obra e reflexão -, a metamorfose que a tradução opera no caso de Shakespeare. Ele confronta um trecho de Henrique IV à tradução de François Victor-Hugo, no século XIX, e comenta o seguinte:

Eis [...] um trecho famoso de Henrique IV. É aquele em que Falstaff está com humor sombrio e se arrepende de sua má vida: “Why, diz para Bardolph, there is it; come, sing me a bawdy song, make me merry... I was as virtuously given as a gentleman need to be; virtous enough, swore little, diced not above seven times a week, went to a bawdy-house not above one in a quarter of an hour, paid money that $i$ borrowed three or four times, lived well, and in good compass; and now i live out of all order, out of all compass" ${ }^{\prime 15}$. Nessas linhas, e no horizonte que sugerem, um mundo de bodegas reais, de tabernas reais, enxergamos um homem real falar de si e a impressão de irrealidade surge apenas na distância que esse homem tenta estabelecer, pelo humor, entre sua verdadeira condição e a ideia que procura dar dela. [...] Vejamos agora uma tradução, uma das mais cuidadosas, a de François Victor-Hugo. Falstaff: “Oui, voilà la chose. Allons, chante-moi une chanson égrillarde. Egaye-moi. J'étais aussi vertueusement doué qu'un gentilhomme a besoin de l'être; vertueux suffisament, jurant peu; jouant aux dés, pas plus de sept fois... par semaine; allant dans les mauvais lieux pas plus d'une fois par quart d'heure; ayant trois ou quatre fois rendu de l'argent emprunté; vivant bien et dans la juste mesure; et maintenant, je mène une vie désordonnée et hors de toute mesure...".16

Eis o mesmo trecho, são as mesmas ideias, as mesmas coisas evocadas. Mas entre o texto em inglês e sua tradução, há uma imensa diferença. Enquanto, em Shakespeare, Falstaff parece estar presente na nossa frente, em seu tradutor parece-nos longínquo, atenuado, ensurdecido, como através de uma vidraça. Não é mais um ser real, é um personagem literário; mas que quer ao mesmo tempo, pela sua linguagem incorreta, parecer demais ao real e acaba por ser menos convincente. Assim todos os personagens de Shakespeare em todas as traduções perderam seu realce. Até mesmo

\footnotetext{
15 “Diabo, deve ser isso; venha, cante uma canção indecente, me alegre... Fui dotado de tanta virtuosidade quanto um cavalheiro precisa ter; virtuoso o bastante, blasfemava pouco, não jogava dados mais de sete vezes por semana, ia ao bordel não mais de uma vez em um quarto de hora, paguei o dinheiro que emprestei três ou quatro vezes, vivi bem e de forma comedida; e agora eu vivo em completa desordem, completamente descomedido."

16 "Sim, eis a coisa. Vamos, cante-me uma canção brejeira. Alegre-me. Eu era tão virtuosamente dotado quanto um fidalgo pode sê-lo; virtuoso o bastante, praguejando pouco; jogando dados, não mais de 7 vezes... por semana; indo em lugares mau frequentados não mais de uma vez em um quarto de hora; tendo três ou quatro vezes devolvido dinheiro emprestado; vivendo bem e numa justa medida; e agora, levo uma vida desordenada e fora de toda medida".
} 
quando os "excessos" shakespearianos, os trocadilhos, as palavras mais triviais são mantidas, esses personagens permanecem fantasmas, para os quais à palavra há falta de ser. "I have immortal longings...", escreve Shakespeare no final de Antônio e Cleópatra. "Je sens en moi l'impatient désir de l'immortalité", escreve Letourneur. "Je me sens pressée d'un violent désir de quitter la vie"17, escreve Francisque Michel. Aonde fomos parar? As palavras não levam mais nem à realidade nem ao mito. É um Shakespeare descorporificado. ${ }^{18}$

"Descorporificado", não há melhor palavra. Claro, na sequência de seu texto, Bonnefoy coloca essa metamorfose descorporificante na conta da língua francesa, clássica demais e que tende demais para as "essências", incapaz de mirar o "concreto" como o inglês. Este seria "aristotélico", e o francês "platônico". Ainda que a tendência essencialista do francês (clássico) seja incontestável, é preciso ir além, ou deslocar a problemática, e dizer que a descorporificação observada por Bonnefoy é imputável, mais profundamente, à tradução em si, que compensa a "falta de ser" por um acréscimo de sentido. Quando um escritor como Edgar Poe escreve: "aos ouvidos de todas aquelas que falam uma outra língua, a maneira de expressar-se de cada nação se destaca por um aspecto ligeiramente grotesco. A tarefa da tradução consiste em corrigir este aspecto se quisermos comunicar o espírito verdadeiro de um autor [...]. Com efeito, não fica mais claro que esta pode comunicar a um estrangeiro uma concepção mais correta do original que o próprio original?" 19, vê-se que o platonismo da tradução "comunicar o espírito verdadeiro..." - não é o apanágio de uma ou outra cultura.

\section{Da língua à "linguagem"}

Talvez pudéssemos dizer que a metamorfose produzida pela tradução se funda no seguinte fato: a língua, aqui, torna-se "linguagem". O original se desloca no elemento emaranhado e intricado da língua, enquanto ser temporal, estratificado, na qual há menos sentido do que significância e ressonância. A tradução, ao fazer passar o texto dessa língua para outra, a

\footnotetext{
17 "Eu sinto em mim o impaciente desejo de imortalidade" / "Sinto-me oprimido por um violento desejo de abandonar a vida".

18 "Shakespeare et le poète français", postface à la traduction de Hamlet, Paris, Mercure de France, 1962, p. 232.

${ }^{19}$ Citado em Gresset: “De la traduction de la métaphore littéraire à la traduction comme métaphore de l'écriture", Revue française d'études américaines, Paris, n. 18, 1983, p. 516.
} 
"eleva" ao nível da linguagem, ou seja, de um sistema composto certamente pelos mesmos elementos, mas articulada de tal maneira que é o unívoco das significações invariantes que predomina. A linguagem é de fato o logos do qual fala a filosofia, que a defina nesses termos ou em termos de "característica" ou de "língua artificial", "bem feita" etc.

Do nosso ponto de vista, esse resultado é a verdade da tradução. Do ponto de vista do senso comum, é o que sempre lhe foi censurado, como se não fosse o "verdadeiro" texto, como se apenas o original possuísse a solidez e concretude que fazem dele um "ser", e não reflexo desse ser. Não obstante, veremos que esse julgamento tradicional sobre a tradução se fundamenta nos mesmos pressupostos que levam, por outro lado, a um julgamento positivo sobre o texto traduzido.

Quando escrevem (foi o poeta inglês Galway Kinnell) que "a tradução sempre deveria ser um pouco mais clara do que o original", identifica-se assim um fenômeno que se produz em qualquer tradução: traduzir generaliza, aclara ${ }^{20}$ e o faz universalizando o sentido, acentuando-o, tornando a língua menos opaca, suprimindo suas espessuras, seus estratos, suas significância e ressonância, em suma, tudo que representa um obstáculo à livre circulação do sentido.

\section{A tradução como movimento meta-físico}

A produção de um logos mais transparente e mais universal, é exatamente o que busca, tradicionalmente, a língua filosófica. Temos agora a primeira definição do elemento "filosófico" da tradução: aquela que foi fixada pelo platonismo. Tal como o pensar platônico, a tradução "deixa cair" a corporeidade elevando-se acima do sensível. Ela vai além e acima do sensível. Além e acima, é exatamente o que diz o verbo alemão para traduzir, übersetzen. Sabemos que o romantismo interpretou especulativamente o verbo übersetzen, na medida em que o ato de colocar, setzen, e de colocar além, über, designam os momentos fundamentais do filosofar. Na medida em que,

\footnotetext{
${ }^{20} \mathrm{O}$ que caracteriza a tradução tradicional não é, em si, a clarificação - que define qualquer tradução mas a sobre-explicitação. Ora existe, no interior mesmo da explicitação, outras possibilidades para o traduzir. Um tradutor quebequense pode defender a prática inversa, que chamou de implicitation [implicitação]. Categoria que merece ser desenvolvida porque assinala um modo não platônico da explicitação traduzinte. Cf. Claude Bédard, "La formulation: les astuces d'un traducteur", Circuit, Montréal, n. 11, 1985, p. 21.
} 
em especial para Novalis, filosofar é de fato colocar-se-acima-e-além. Em sua linguagem: elevar à potência, potenzieren.

Certamente, übersetzen é primeiro a "tradução" do latim translatio, que designa antes uma transferência lateral, horizontal. Mas a este movimento de transferência horizontal se sobrepõe um movimento de translação vertical (para o alto), de tal modo que o ato de traduzir poderia ser representado como segue:

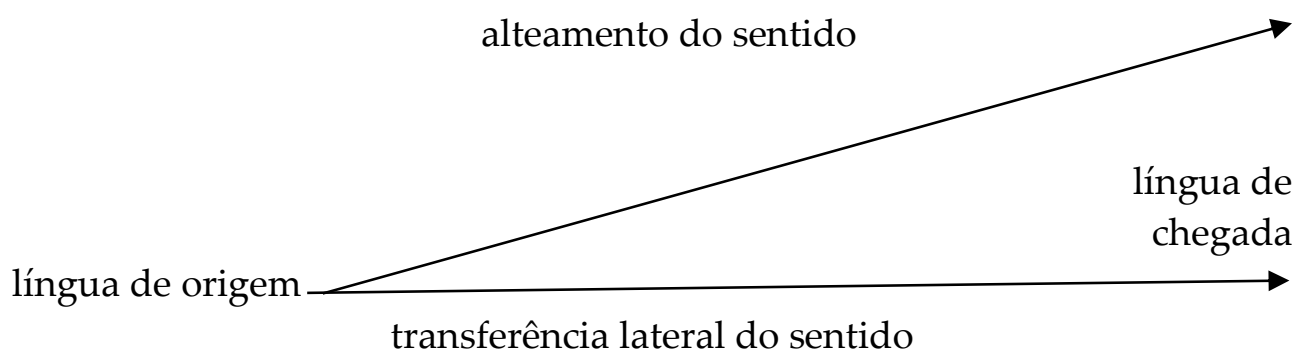

Ao se estabelecer que a tradução deve ser mais clara que o original, abandona-se o eixo horizontal para o eixo vertical. E vamos observar imediatamente que outro eixo vertical se abre, mas esta vez abaixo do eixo horizontal:

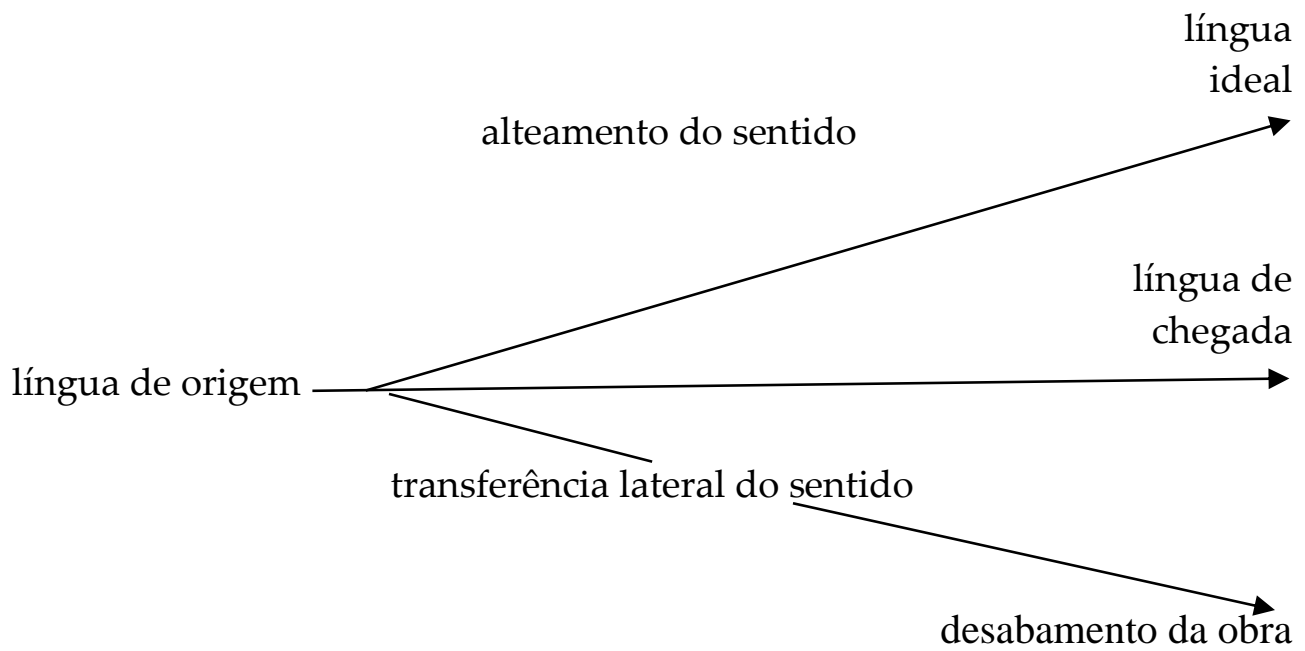




\section{O embelezamento}

Mas antes de falar desse "desabamento" que se produz na e pela tradução, vejamos qual é a terceira metamorfose operada pela tradução, que chamaremos, como se fez na idade clássica, o "embelezamento". Certamente, nos clássicos, esse conceito está ligado a uma estética do gosto e da literatura. Mas essa estética, para não parecer uma simples "moda" histórica, deve ser relacionada àquilo que a funda filosoficamente: o elo do "verdadeiro" e do "belo". Quero dizer com isso que a "liberação" do sentido que se produz na tradução não pode ser senão um "embelezamento". Tal seria a significação máxima do chiste ${ }^{21}$ de Nietzsche segundo o qual ele acha Schopenhauer menos "pesado" (e mais "claro") em francês do que em alemão. Traduzir Schopenhauer em francês ao estabelecer, como o faz Nietzsche, que nossa língua clássica é mais próxima do "logos", é espiritualizá-lo. Ora, o peso da língua de origem não é apenas irracionalidade e confusão, é também ausência de graça e de "elegância". A tradução de Schopenhauer libera da pesada canga "germânica" os pensamentos do filósofo. E o que a tradução libera, não é somente a verdade racional do conteúdo, mas a forma de sua logicidade. É nesse ponto que reencontramos o "belo". No sentido em que Platão fala de um "belo raciocínio matemático", em que Schlegel fala da "beleza lógica". À beleza material do texto original se opõe a beleza formal da tradução na qual a pura articulação dos pensamentos finalmente resplendece harmoniosamente. Estamos aqui em pleno platonismo, já que, para Sócrates, o Belo é "o que há de mais brilhante" (Fedro). A racionalização traduzinte que aproxima um texto de sua verdade, torna-o necessariamente "belo", mas, ainda assim, falamos daquela figura da beleza que deve ser chamada de "beleza formal". Essa figura da beleza se resume ao seguinte, fazer aparecer a pura forma: ordem e encadeamento das partes, harmonia, equilíbrio, pausas e retomadas bem localizadas etc. Em

\footnotetext{
${ }^{21} \mathrm{O}$ termo "boutade", empregado por Berman, significa, em francês, uma tirada espirituosa, um rasgo de engenhosidade. Minha primeira decisão foi a de evitar o emprego da palavra "piada", por ser genérica e simplificar a complexa questão do humor. O caminho foi seguir, a partir de uma dica da Simone Petry, o problema da tradução do termo witz, em alemão, no campo da psicanálise. Witz foi vertido para "chiste", em português, no título da obra de Freud: Os chistes e sua relação com o inconsciente. Por sua vez, Lacan prefere usar a expressão "trait d'esprit" (Witz) a "mot d'esprit" da tradução francesa: Le mot d'esprit et ses relations avec l'inconscient. A tradutora do Seminário (livro 5 - As formações do inconsciente, Zahar, 1999) de Lacan optou por diferenciar as duas expressões mantendo witz para trait d'esprit e usando chiste para mot d'esprit. Escolhi, portanto, o uso de chiste ao invés de boutade, mesmo se este existe em português (dicionarizado), por entender a palavra como um conceito empregado na psicanálise, cuja tradução é sujeita a debates. Procurei restituir o diálogo que Berman estabelece com a psicanálise e a filosofia.
} 
suma, tudo o que dá a impressão, ao ler, que a obra é plenamente mestre de si mesma, e que banha no que Novalis chamou "o puro presente do espírito", puro presente que não pode ser senão a presença do espírito para si mesmo no seio de um médium transparente. O que o poeta expressou ainda ao dizer: "o espírito não pode se manifestar senão em uma forma estrangeira e aérea"22, e que podemos referir, aqui, diretamente à tradução. A clareza sem sombra na qual flutua o sentido é em si beleza. O ato de traduzir é o que permite ao "espírito" se manifestar, pois a língua que ele produz é de fato simultaneamente "estrangeira" e "aérea".

Com essas considerações especulativas, não estaríamos muito afastados da prática empírica dos tradutores? De forma alguma. Pois quando nos dizem que uma tradução deve ser "clara" e "elegante" (e não param de afirmá-lo), nos encontramos em pleno platonismo (e, também, em pleno cartesianismo). Sem saber disso. Clareza e elegância formam um par. A clareza remete ao fato de que o sentido aparece mais puramente do que no original. A elegância, por sua vez, remete à forma dessa aparição. $O$ texto traduzido deve simultaneamente cintilar, ser harmonioso e nos tocar. E é sua elegância que nos toca. A elegância sempre remete à forma e ao movimento da forma: movimento em que tudo é fluído, fácil, corrente, em que tudo se mostra dessa maneira. Se, no domínio físico, a elegância é sinal de domínio do corpo "bem-vestido", no domínio da língua, ela é igualmente o sinal de que a forma sabe dominar o conteúdo. Que a tradução, enquanto captação do sentido, seja ipso facto embelezadora, isso explica porque, a rigor, é impossível traduzir "tal qual" um texto mal escrito, mesmo que seja possível fazê-lo, pois isso colide de frente com a visada do ato de traduzir, seu desejo mais profundo. Isso comprova perfeitamente que, aqui, estamos no espaço das transformações, e não da busca por hipotéticas "equivalências". Além disso, o mesmo tradutor que se desespera para criar o equivalente de um poema de Pouchkine, não hesita em "pentear" a prosa "hirsuta" de um Tolstói. Esse espaço de transformações, é aquele onde a tradução tem por tarefa "enfatizar" o que, no original, é da ordem do verdadeiro e do belo. Nietzsche diz em algum lugar que "idealizar" é proceder a uma "imensa erosão

22 "l'esprit ne peut se manifester que dans une forme étrangère et aérienne". Em Grains de Pollen, citado em L'Épreuve de l'étranger, p. 262. 
dos contornos". A tradução é, de fato, essa "erosão" que libera as grandes linhas da obra.

É igualmente nesse sentido que se diz empiricamente que, para um texto, a tradução é uma "prova de verdade". Observamos, aliás, como o empirismo enuncia desordenadamente julgamentos contraditórios sobre a tradução, como traduttore tradittore e a tradução "prova de verdade", sem nunca procurar o fundamento comum desses enunciados. A tradução é uma prova de verdade, pois ela faz aparecer as qualidades e os defeitos do original. Isso é seguro. Mas se produz com mais frequência o seguinte: assim que o tradutor descobriu os pontos fracos do texto, ele se precipita para lançar sobre eles o véu do sentido e do ser: faz aparecer as belezas, e desaparecer os defeitos. O platonismo da tradução tangencia a retórica sofística. Certamente, o tradutor dirá também, como A. W. Schlegel, que ele quer reproduzir até mesmo as "sardas de sua bela", mas essas sardas, que encarnam a materialidade do original, todo o espírito de sua operação tende a apagá-las. Daí duas consequências: o desprezo em que são mantidos os "maus" tradutores fascinados pela "letra", e o conflito que surge quando o original possui, igualmente, uma inegável beleza.

\section{O conflito da beleza material e da beleza formal}

Aqui, duas figuras de beleza se opõem: a beleza material e a beleza formal. A beleza de um original é sempre material, até mesmo quando se pode descrevê-la em termos "formais". Mais ainda, a beleza formal, quando caracteriza um original, arruína seu caráter de obra, e é o que ocorre com os escritos ditos "acadêmicos": são belos, mas "frios" e "ocos". Ora, na tradução, a beleza formal é sinal de excelência. O que se passa então quando o tradutor lida com um original cuja beleza material é muito evidente? Há conflito entre a exigência da transmissão desta beleza e a outra exigência, que privilegia a beleza formal enquanto marca do texto traduzido como tal. Esse embate assinala o ponto no qual a tradução, para não trair o original, deve se voltar contra sua própria essência, aquebrantar nela mesma o impulso em direção de uma beleza formal.

Esse movimento de virada, Bonnefoy o tematizou magnificamente em sua poesia: 
Celle qui ruine l'être, la beauté, sera suppliciée, mise à la roue, déshonorée, dite coupable, faite sang et cri, et nuit, de toute joie dépossédée - Ô déchirée sur toutes les grilles d'avant l'aube. ${ }^{23}$

[Aquela que arruína o ser, a beleza, será supliciada, posta na roda, desonrada, dita culpada, feita sangue e grito, e noite, de toda alegria despossuída

- Oh dilacerada sobre todas as grades de antes da aurora.]

As hesitações de um Rivarol frente aos textos de Dante revelam, de maneira exemplar, o conflito do qual estamos falando, mesmo se Rivarol acaba privilegiando a beleza formal:

[...] o tradutor de Dante tem que lutar incessantemente contra um estilo afaimado por poesia, que é rico e pouco delicado. [...] Portanto, qual partido tomar? [...] Confesso que todas as vezes que o palavra por palavra oferecia apenas tolice ou uma imagem repugnante, tomei o partido de dissimular; mas era para aderir mais estreitamente a Dante, mesmo quando eu me afastava de seu texto: a letra mata, e o espírito vivifica. Ora produzi apenas a intenção do poeta, e deixei ali sua expressão; ora generalizei a palavra, ora restringi o sentido; não podendo oferecer uma imagem de frente, procurei mostrá-la de perfil ou seu reverso. ${ }^{24}$

Mas se a tradução manifesta o "verdadeiro" da obra na irradiação de uma pura forma, aparentada nesse ponto com a filosofia, como é possível que não compartilhe em nada a dignidade e a glória do ato filosófico? Que o que nela é da ordem do platonismo seja considerado como sua verdade, certamente, mas também fustigada como uma traição?

\footnotetext{
${ }^{23}$ Bonnefoy, Poésies, Paris, Mercure de France, p. 136.

24 "le traducteur de Dante a sans cesse à lutter contre un style affamé de poésie, qui est riche et point délicat. [...] Quel parti donc prendre? [...] J'avoue que toutes les fois que le mot à mot n'offrait qu'une sottise ou une image dégoûtante, j'ai pris le parti de dissimuler; mais c'était pour me coller plus étroitement à Dante, même quand je m'écartais de son texte: la lettre tue et l'esprit vivifie. Tantôt je n'ai rendu que l'intention du poète, et laissé là son expression.; tantôt j'ai généralisé le mot, et tantôt j'en ai restreint le sens: ne pouvant offrir une image de face, je l'ai montrée par son profil ou son revers". Citado por G. Mounin, Les belles infidèles, p. 22.
} 


\section{A tradução como destruição do ser da obra}

Ao manifestar o verdadeiro do texto sob a face do belo, a tradução simultaneamente corrompe de forma radical o ser do original. Mais precisamente, ela o faz ingressar no domínio da corruptibilidade e da perecibilidade. Isso fica evidente se forem considerados os atributos tradicionais da obra enquanto obra: durabilidade ou imperecibilidade, intangibilidade, unicidade, ser etc. Pois os atributos correlativos da tradução são exatamente inversos: perecibilidade, modificabilidade, multiplicidade, devir. Aqui, portanto, reviravolta total: é a obra que possui todos os predicados da Ideia platônica, e o texto traduzido aqueles do "sensível".

Mas por que a tradução eleva a obra à glória do sentido puro e a precipita ao mesmo tempo na perecibilidade? Justamente porque ela mergulha no re-formulável. Se a multiplicidade, a mobilidade do texto traduzido se opõem ao ser da obra (aqui, ser significante: o que repousa duravelmente em si mesmo), é porque ele pode ser "outro". Por um lado, o que libera o sentido destrói o ser, a consistência da obra. Estamos, aqui, no coração do que Ortega y Gasset chamava de "o esplendor e a miséria" da tradução, em referência ao romance de Balzac, Esplendores e misérias das cortesãs (uma referência que não é desprovida de sentido para a tradução, se pensarmos nas "belas infiéis"). Se a tradução tem por visada produzir o "verdadeiro" do texto, um texto que se desenrola em um médium "estrangeiro" e "aéreo", o resultado é que não cria um "verdadeiro" texto, ou seja, um texto repousando em si mesmo e no fundo da língua. Repousar sobre si mesmo, para um texto, não significa remeter a outro texto e excluir qualquer possibilidade de ser outro. Ora, o texto traduzido remete a outro texto e sempre pode ser outro, justamente por causa dessa remissão. É por esse motivo que ele jamais é considerado como uma obra, ainda que destacasse o "verdadeiro" de uma obra, ainda que fosse mais próximo - isso acontece - do que o original da verdade do texto, ainda que - isso também acontece - sua forma fosse mais bela. $O$ texto da tradução detém seu ser de um "outro", e isto remete à distinção aristotélica (que tem sua origem em Platão) de o ser-por-si e o ser-pelo-outro; a Ideia é por si, a coisa sensível por um outro do qual é apenas um semblante, o duplo e a cópia. Nesse ponto, de novo, a tradução tem o mesmo estatuto ontológico degradado que o sensível em Platão: pois o sensível, no platonismo, é semblante, reflexo, duplo e cópia. A tradução é como a lua: detém sua 
claridade do sol (original) e, portanto, brilha com uma luz emprestada e mais fraca.

\section{Valorização e desvalorização da tradução no platonismo}

Ou antes, porque aqui tudo não passa de desequilíbrio, vale dizer: ela é o que a lua é para o sol, mas é também esse espelho que concentra de forma mais potente os raios do sol. É "mais verdadeira" e "menos verdadeira". Empiricamente, isso é verificável: muitos autores têm a impressão de que a tradução realmente embelezou, aclarou, purificou sua obra, enquanto que a crítica e o público, por sua parte, não enxergam nada a priori senão uma pálida cópia do original julgado a priori mais resplandecente.

Compreende-se também que a valorização do texto traduzido se encontre, sobretudo, historicamente, nos filósofos ${ }^{25}$ : não por lhes faltarem sentido literário, mas porque percebem de forma confusa que "sua coisa", o logos, o sentido, o "presente do espírito", realmente aparece e brilha pela tradução. Os filósofos elogiam o que há de "filosófico" (de sombra projetada da filosofia) na tradução.

No horizonte categorial que nos legou o platonismo, a tradução, portanto, é simultaneamente valorizada e desvalorizada. E enquanto a pensarmos exclusivamente no interior desse horizonte, enquanto os tradutores a conceberem como ato que tende para o "verdadeiro" e o "belo", para a radiante idealidade do sentido, não poderá ser diferente.

\footnotetext{
${ }^{25}$ Encontramos tais julgamentos relativamente positivos sobre a tradução e seus resultados em Descartes, Novalis, Hegel, Nietzsche et até mesmo em Marx, que preferia a versão francesa do Capital ao original em alemão.
} 